\title{
Outcomes of a Care Coordination Guardianship Intervention for Adults with Severe Mental IIIness: An Interrupted Time Series Analysis
}

\author{
Eliot Levine $^{1} \cdot$ Catherine Jett $^{2}$ D $\cdot$ Jeremiah Johnson ${ }^{2} \cdot$ Heather Connors $^{3}$
}

Published online: 20 December 2019

(c) The Author(s) 2019

\begin{abstract}
This study investigates the impacts of an intensive care coordination intervention for adults with severe mental illness who have guardians. Program impacts on medical and legal outcomes were assessed using interrupted time series analysis. Program participation was associated with statistically significant reductions in the level and trend of psychiatric hospitalizations, number of days in psychiatric hospitals, emergency room visits, and arrests. Days incarcerated did not change significantly. The decrease in medical and legal outcomes may be associated with decreased spending on these services. The program and other intensive care coordination interventions for this population warrant further replication and research.
\end{abstract}

Keywords Guardianship · Care coordination · Chronic mental illness · Program evaluation

\section{Introduction}

Guardians are court-appointed representatives who have the authority to make legal, medical, and financial decisions for individuals who lack the capacity to make essential decisions for themselves. The appointment of a guardian is intended to improve the client's quality of life through activities such as securing needed medical care or equipment, paying bills, resolving legal issues, enhancing socialization opportunities, helping to establish a residence, and providing emotional support (Teaster et al. 2009; Vera Institute of Justice 2015).

A subset of these findings was presented on November 18, 2018, as part of the following panel discussion: Jett, C., Levine, E., \& Capitani, J. (2018, November). Cost-benefit analyses of providing guardians to hospital patients and guardianship program participants. In J. Moye (Chair), Decision making for those without capacity and surrogates: Legal, financial, and healthcare perspectives. Symposium conducted at the Annual Scientific Meeting of the Gerontological Society of America, Boston, MA.

Catherine Jett

cjett@donahue.umassp.edu

1 Aurora Institute, 1934 Old Gallows Road, Suite 350, Vienna, VA 22182-4040, USA

2 Applied Research and Program Evaluation, University of Massachusetts Donahue Institute, 100 Venture Way, Suite 500, Hadley, MA 01035, USA

3 Guardian Community Trust, One Elm Square, Suite 2D, Andover, MA 01810, USA
Advocates have also argued that effective guardianship interventions can reduce costs to public and private entities, primarily by reducing expenditures for health and legal services (Burley 2011).

Numerous guardianship program models exist, and understanding their effectiveness for particular populations is essential to guide decision-making by guardians, care coordinators, judicial personnel, program funders, and policy makers. We studied the effectiveness of a program for adults whose mental illness has reached a level of severity where a guardian has been appointed by the probate court. Developed in 2001 by a steering committee of Connecticut mental health, criminal justice, legal, and academic professionals, the program uses a care coordination approach known as the Guardian Model and is implemented by Guardian Ad Litem Services, Inc. (GAL) in Connecticut (Mackniak 2016). The model was developed with the dual goal of improving client outcomes and improving service efficiency to reduce costs for medical, mental health, and criminal justice services.

Implementing care coordination approaches is a high priority of the health and mental health systems nationally (McDonald et al. 2004). The Guardian Model is designed as an independent program that facilitates coordination among the multiple providers who serve each program client. Desired client outcomes include meaningful community involvement, stable housing, adherence to medical and clinical prescriptions, and reduced involvement with the criminal justice system. The Guardian Model program is unique 
among those serving individuals with serious mental illness (SMI) in its intensive degree of care coordination and supports provided to the participants and their guardians; understanding the effectiveness of this program has implications for investments in supporting guardians of individuals with SMI more broadly.

Participants in the Guardian Model program must be referred by the State of Connecticut Department of Mental Health and Addiction Services (DMHAS), have a guardian appointed by the probate court, have an Axis I DSM-5 diagnosis other than or in addition to substance abuse or dependence (American Psychiatric Association 2013), and be involved with multiple services and supports with minimal success. The program was designed for individuals identified by DMHAS as high risk clients; those referred often have a history of frequent emergency room visits or arrests, and DMHAS has been unable to engage them. The program is intended to support guardians-typically family members or attorneys appointed by the court-who may lack knowledge of social service systems or lack the capacity to support the client fully due to emotional attachments to the client, competing demands, or minimal compensation. The guardian authorizes program staff to communicate with service providers and obtain important information about the client. Program staff in turn keep the guardian informed in real time about the person under guardianship, educate the guardian about navigating social service and legal systems, bring comprehensive information to bear on any decisions the guardian must make, and assist them in advocating for their client.

The program begins with a psychosocial assessment based on client report and chart review, and an intake period with weekly to biweekly meetings with a project social worker to engage the client and build rapport. After the intake period, the program develops a care plan with input from the client and all service providers. Then program staff maintain regular contact with the client, guardian, and service providers to implement the plan and adapt it as the client's circumstances change or additional needs are identified.

The social worker engages in a wide variety of support and coordination activities. These include contacting service providers weekly, visiting the client in their place of residence at least monthly and calling them biweekly, attending and encouraging the client to attend all treatment planning meetings, scheduling treatment plan reviews in response to concerns with services or the client's level of functioning, encouraging the client to voice concerns and communicate with the guardian and service providers, administering evaluation instruments every 6 months to determine the client's level of life and service satisfaction, informing guardians of the client's level of functioning, making recommendations to the guardian to seek warrants to have the client examined for psychiatric stability if necessary, making recommendations for in-court reviews and case conferences with the entire treatment team when additional services are needed, and working with providers to secure high-quality services. In short, the Guardian Model entails an intensive care coordination approach to support guardians in maximizing the client's access to appropriate, quality services in their communities. At the same time, it encourages clients to participate as fully as they are able in determining the course of their treatment and their lives.

Using data that GAL gathers about each client's current and past health and legal outcomes, as well as demographic and administrative data, the current study evaluated whether an extended period of program participation was associated with changes in psychiatric hospitalizations, days hospitalized, emergency room visits, arrests, and days incarcerated. Changes in these indicators were also used to provide rough estimates of fiscal impacts of program participation.

\section{Methods}

Since its inception, GAL has collected medical, psychiatric, and legal data about the program's clients, primarily to guide clinical work and inform court hearings. We used these datasets to assess the program's association with intended changes in client outcomes. When a new client enrolls in the program, GAL engages in an extensive process of gathering historical records of each client's psychiatric hospitalizations, arrests, emergency room visits, and incarcerations. These records are compiled from patient, guardian and family interviews, as well as data provided by the Connecticut Department of Corrections and Connecticut Department of Mental Health and Addiction Services. GAL also gathers information about new incidents while the client is participating in the program. Data are not available for new incidents that occur after a participant has left the program.

Our study sample consists of all GAL clients who stayed in the program for at least three consecutive years after their initial enrollment and whose records included all of the additional variables used in the analyses. Of the $423 \mathrm{GAL}$ clients who had enrolled by 11/30/14 - in time to have 3 years of follow-up data-203 were excluded because they did not remain enrolled for three consecutive years, and three participants were excluded from analysis due to missing data on one or more variables. We used interrupted time series analyses, a longitudinal quasi-experimental design, to evaluate whether the program was associated with improved client outcomes immediately and over time (Cook and Campbell 1979).

Each time series model utilized annual outcome data from the four years prior to program enrollment and for the first 3 years of program participation. A multilevel mixed effects 
regression with time periods nested within clients, controlling for covariates of interest, was used to model changes in several indicators over time (Snijders and Bosker 2012). Due to the limited number of observations available, the time series analysis was not adjusted for autocorrelation (Cochrane Effective Practice and Organisation of Care 2017). However, month of program entry was entered as a covariate to control for seasonal effects, and date of program entry was entered to control for program maturation effects. Additional covariates included gender, race/ethnicity, and age at program enrollment.

Income data was available for only $82 \%$ of the sample and was not included in primary analyses; however, the same time series analyses were conducted with this smaller group, including income as a covariate, and statistical significance of program impacts did not change. Client income reported at the month and year of initial program enrollment was adjusted to 2015 dollars based on the Consumer Price Index (CPI) using the CPI Inflation Calculator of the Bureau of Labor Statistics (2018).

Findings of the time series analyses were used to calculate two estimates of changes in spending on medical, mental health, and criminal justice services due to changes in observed and predicted numbers of emergency room visits, days hospitalized, and days incarcerated. Cost estimates associated with arrests were not available. The "maximum estimate" assumed that the pre-intervention trend would have continued in the absence of intervention; it was based on the difference between the predicted and observed values for the first post-intervention year. The "conservative estimate" assumed that the pre-intervention trend would not have continued in the absence of intervention; it was based on the difference between the observed values for the last pre-intervention year and the first post-intervention year.

These differences were multiplied by estimates of the cost per incident to estimate the change in spending in the first post-intervention year. The cost per day of psychiatric hospitalization was derived from Connecticut Department of Public Health (2015) data, the cost per day of incarceration in Connecticut was obtained from a published report (Vera Institute of Justice 2015), and the cost of an emergency room visit for a psychiatric patient was obtained from a published study of a hospital in another state (Nicks and Manthey 2012).

\section{Findings}

\section{Sample and Program Characteristics}

The study sample $(\mathrm{N}=217)$ was $68 \%$ White, $25 \%$ Black/ African American, 5\% Hispanic/Latino, and 2\% other. Fifty-six percent were male, and $99 \%$ spoke English as their primary language. The average age at enrollment was 43 years, with a standard deviation of 14 years. All clients were diagnosed with at least one major mental illness, including $77 \%$ with schizophrenia or schizoaffective disorder and $11 \%$ with major depression or bipolar disorder. Monthly income information was available for $82 \%$ of the sample; median monthly income was $\$ 1010$, adjusted to 2015 dollars using the CPI. This corresponds to $103 \%$ of the 2015 federal poverty level for an individual. For the 3 years of program data analyzed, GAL provided an average of 63 hours of services per client per year.

\section{Changes in Client Outcomes}

The intervention was associated with statistically significant improvements in both the level and trend of four out of five client outcomes-psychiatric hospitalizations, number of days in psychiatric hospitals, emergency room visits, and arrests (Fig. 1 and Table 1). For example, psychiatric hospitalizations decreased by 1.15 per client in the first post-intervention year (95\% CI -1.42 to $-0.88, \mathrm{p}<0.001)$, and the trend in annual hospitalizations-which had been increasing-reversed, decreasing by 0.33 hospitalizations per year ( $95 \% \mathrm{CI}-0.48$ to $-0.18, \mathrm{p}<0.001)$. For the fifth outcome, number of days in jail, significant changes were not observed for level or trend. These impacts were found after controlling for the effects of gender, race/ethnicity, age at program enrollment, and date and month of program entry.

Observed and predicted values for each client outcome are shown in Table 2. For example, participants spent an average of 81.9 days in a psychiatric hospital in the year before intervention. Based on the increasing trend prior to intervention, time series analysis predicted an increase to 87.6 days in the subsequent year, but the observed value was 59.2 days.

\section{Estimated Change in Spending}

Reductions in days hospitalized, emergency room visits, and days incarcerated suggest that the intervention was associated with substantially reduced service costs for the set of common medical, mental health, and criminal justice outcomes tested. The conservative estimate of change in spending for program participants in their first year is a reduction of $\$ 85,808$ per client and $\$ 18.6$ million total for the 217 clients in the sample (Table 3). The maximum estimate of first-year change in spending is a reduction of $\$ 106,699$ per client and $\$ 23.2$ million total. ${ }^{1}$ The reduced number of days

\footnotetext{
${ }^{1}$ Due to the rising post-intervention trend for days incarcerated, this component of total change in spending is lower for the maximum estimate than for the conservative estimate.
} 


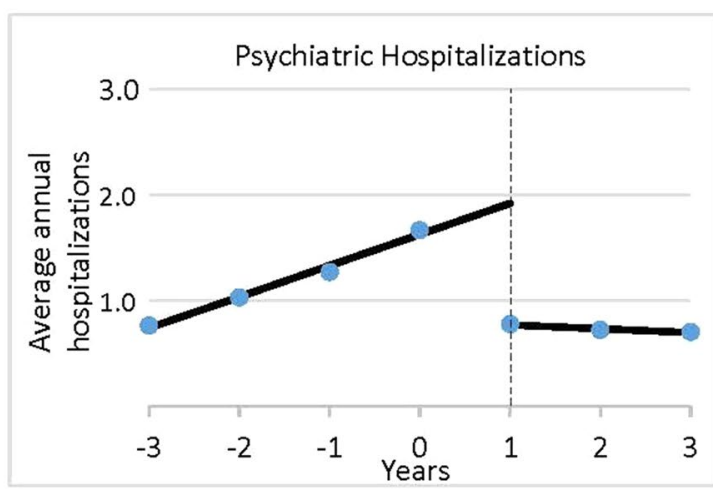

$p<0.001$ for value and trend

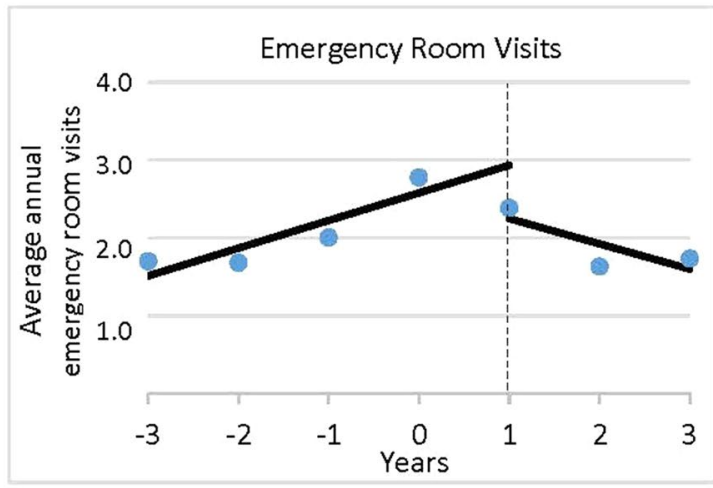

$p=0.045$ for value; $p<0.001$ for trend

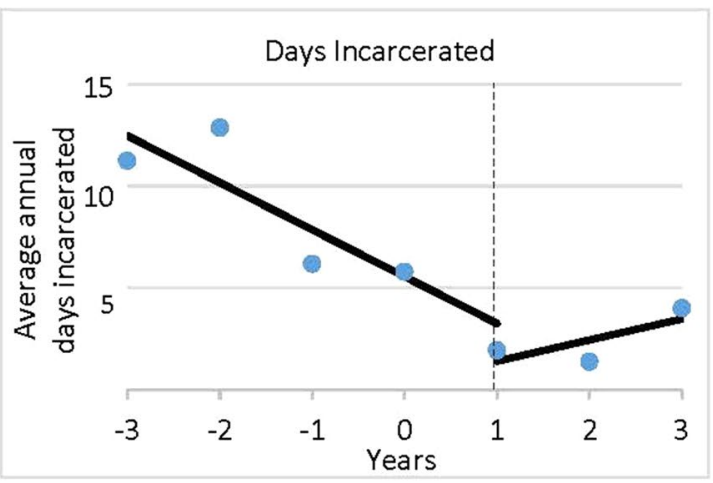

Value and trend not significant.

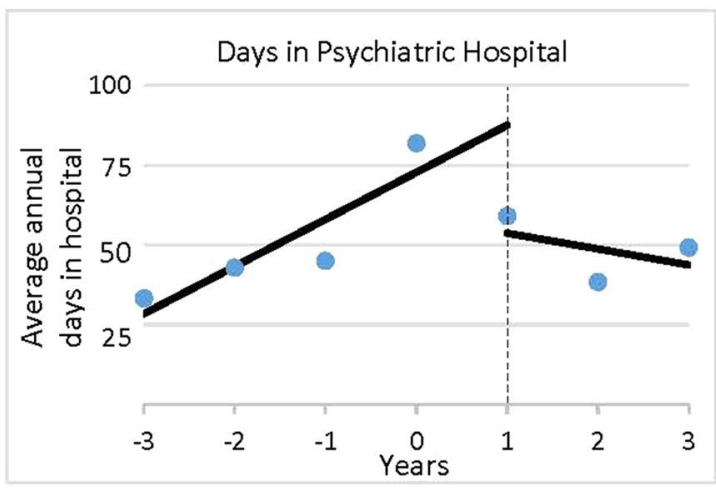

$p=0.021$ for value; $p=0.014$ for trend

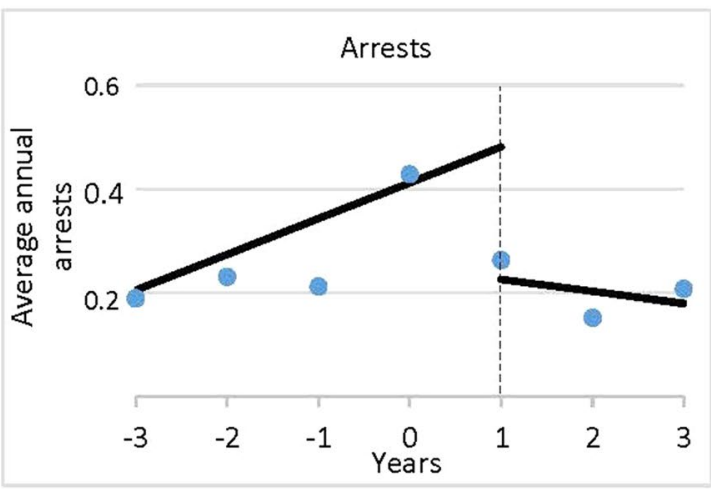

$p=0.001$ for value; $p=0.026$ for trend

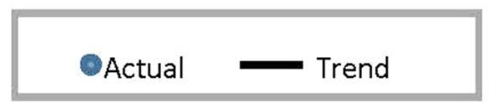

Fig. 1 Level and trend of client indicators before and after program enrollment. Year 1 shows the value for the first year of program enrollment. $\mathrm{P}$-values are for the change in value during the first year of enrollment, and the change in trend before and after enrollment

spent in psychiatric hospitals account for $99 \%$ of this change. The estimated first-year change in spending for the study sample were realized across multiple calendar years, as the study includes clients who enrolled in the program across a 13-year period.

The decreasing post-intervention trends (Fig. 1) suggest that decreased spending for these services would continue over time, and that the decrease would be slightly larger in the second and third years of program participation. While cost estimates are not the primary focus of this study, this preliminary analysis suggests that there is a reduction in spending related to medical, mental health, and criminal justice outcomes. By comparison, the average annual cost of program participation is about $\$ 6000$ per client, based on the total cost of the program and the number of clients served from 2014 to 2016 (Mackniak 2016). 
Table 1 Change in psychiatric, medical, and criminal justice incidents after program enrollment

\begin{tabular}{|c|c|c|c|c|c|c|c|c|}
\hline \multirow[t]{2}{*}{ Incident type } & \multicolumn{4}{|c|}{ Change in level } & \multicolumn{4}{|c|}{ Change in trend } \\
\hline & Mean & LCI & UCI & $\mathrm{p}$ & Mean & LCI & UCI & $\mathrm{p}$ \\
\hline Psychiatric hospitalizations & -1.149 & -1.423 & -0.875 & $<0.001$ & -0.332 & -0.482 & -0.182 & $<0.001$ \\
\hline Days in psychiatric hospital & -33.872 & -62.707 & -5.036 & 0.021 & -19.765 & -35.559 & -3.972 & 0.014 \\
\hline Emergency room visits & -0.687 & -1.360 & -0.015 & 0.045 & -0.681 & -1.049 & -0.312 & $<0.001$ \\
\hline Arrests & -0.256 & -0.404 & -0.108 & 0.001 & -0.092 & -0.173 & -0.011 & 0.026 \\
\hline Days incarcerated & -1.854 & -10.100 & 6.392 & 0.659 & 3.342 & -1.175 & 7.859 & 0.147 \\
\hline
\end{tabular}

"LCI" and "UCI" are the lower and upper limits of the 95\% confidence interval

Table 2 Observed and predicted outcomes before and after intervention

\begin{tabular}{lccc}
\hline Outcome & \multicolumn{2}{l}{ Average number of incidents } \\
\cline { 2 - 4 } & $\begin{array}{l}\text { Pre-intervention year- } \\
\text { observed }\end{array}$ & $\begin{array}{l}\text { Post-intervention year- } \\
\text { predicted }\end{array}$ & $\begin{array}{l}\text { Post-intervention } \\
\text { year-observed }\end{array}$ \\
\hline Psychiatric hospitalizations & 1.7 & 1.9 & 0.8 \\
Days in psychiatric hospital & 81.9 & 87.6 & 59.2 \\
Emergency room visits & 2.8 & 2.9 & 2.4 \\
Arrests & 0.4 & 0.5 & 0.3 \\
Days incarcerated & 5.8 & 3.2 & 1.9 \\
\hline
\end{tabular}

Table 3 Estimated changes in spending associated with program participation

\begin{tabular}{|c|c|c|c|c|c|}
\hline \multirow[t]{2}{*}{ Outcome } & \multirow[t]{2}{*}{ Estimated cost per incident } & \multicolumn{2}{|c|}{ Conservative estimate } & \multicolumn{2}{|l|}{ Maximum estimate } \\
\hline & & $\begin{array}{l}\text { First-year change } \\
\text { per client }\end{array}$ & $\begin{array}{l}\text { Total first-year } \\
\text { change }(\mathrm{N}=217)\end{array}$ & $\begin{array}{l}\text { First-year change } \\
\text { per client }\end{array}$ & $\begin{array}{l}\text { Total first- } \\
\text { year change } \\
(\mathrm{N}=217)\end{array}$ \\
\hline Psych. hospitalizations & $\$ 3715$ per day $^{\mathrm{a}}$ & $-\$ 84,572$ & $-\$ 18,352,100$ & $-\$ 105,665$ & $-\$ 22,929,223$ \\
\hline Emergency room visits & $\$ 1482$ per visit $^{\mathrm{b}}$ & $-\$ 581$ & $-\$ 125,970$ & $-\$ 809$ & $-\$ 175,649$ \\
\hline Days incarcerated & $\$ 170$ per day $^{c}$ & $-\$ 656$ & $-\$ 142,290$ & $-\$ 225$ & $-\$ 48,875$ \\
\hline Total & & $-\$ 85,808$ & $-\$ 18,620,360$ & $-\$ 106,699$ & $-\$ 23,153,747$ \\
\hline
\end{tabular}

${ }^{\text {a }}$ Connecticut Department of Public Health (2015)

${ }^{b}$ Nicks and Manthey (2012); adjusted for inflation to 2015 dollars

${ }^{\mathrm{c}}$ Vera Institute of Justice (2015)

\section{Discussion}

In this study, a quasi-experimental approach demonstrated that intensive care coordination was associated with substantial positive changes in health and legal outcomes for adults with severe mental illness who require a guardian. These changes may imply not only decreased spending, but also improved quality of life for those clients. The positive findings suggest that the Guardian Model may merit replication and further research in Connecticut and other settings.

More generally, the findings support intensive care coordination efforts that go well beyond the minimal or moderate case management efforts reportedly carried out by some guardians (Moye et al. 2016). While some guardians do provide intensive care coordination, many lack the resources or professional knowledge to meet the complex needs of the person under guardianship. Programs like the Guardian Model that substantially supplement the guardian's efforts may lead to improved client outcomes and cost savings. Similar results may also be achievable by well-trained and deeply engaged guardians who receive a level of compensation and support that enables them to devote sufficient time to care coordination efforts.

Implementation research is needed to identify the diverse program activities, structures, staffing, and collaboration with other agencies that lead to positive outcomes. One question for future effectiveness research is whether the observed outcomes persist beyond three years; while the 
3-year post-intervention trend was favorable, the observed level of incidents rose slightly for four of the five outcome indicators in the third year post-intervention compared to the second year. Another question is why arrests were increasing prior to intervention, while days incarcerated were trending downward. A possible explanation offered by GAL personnel was that prior to program enrollment, as individuals' psychiatric conditions were worsening, arrests may have led to psychiatric hospitalizations rather than incarceration.

The study also provided preliminary estimates of changes in spending associated with the Guardian Model. The decrease in spending from reduced medical, mental health and criminal justice outcomes appears to be greater than the cost of the intervention, suggesting that the economic viability of the program warrants further investigation. Further research could refine the methodology for developing cost estimates and incorporate additional factors. For example, accounting for the costs of caring for inmates with severe mental illness could result in a larger estimate of reduced spending. Conversely, accounting for the cost of providing extra services in community settings to clients who spend fewer days hospitalized could result in a smaller estimate of reduced spending.

One limitation of the current study is the lack of a comparison group that did not receive the Guardian Model intervention. It would not be possible to have a no-intervention comparison group, because a valid comparison group would also have severe mental illness and would likely be receiving other support services. Nonetheless, future research could utilize comparison groups to measure the impacts of the Guardian Model against the impacts of other interventions.

Another limitation is that the time series models required at least three time points after the intervention, meaning the study excluded GAL participants who left the program prior to 3 years of enrollment. This could potentially have biased the results. However, baseline outcomes in the year prior to program enrollment were not statistically significantly different between those in the study sample and those who were excluded because they did not remain in the program for three years. Demographics were also comparable, with age at enrollment being the only significant difference (those excluded were four years older, on average). Further, GAL participants enrolled for 1 to 2 years did not have statistically significantly different outcomes during the first year of the intervention compared to the study sample.

Despite these limitations, the interrupted time series analysis in the current study compared average pre-intervention patterns to average post-intervention patterns of key medical and legal indicators for many individuals, thereby using a quasi-experimental design to provide evidence of the program's effectiveness. The associations between the participation in the Guardian Model and improved outcomes should be interpreted with caution, given the inherent limitations of the study design. Yet these initial findings suggest that the Guardian Model is effective for those enrolled for at least three years, implying that the program merits further research and, potentially, replication.

Funding This study was funded by Guardian Community Trust, a nonprofit organization.

\section{Compliance with Ethical Standards}

Conflict of interest All authors declare that they have no conflict of interest.

Ethical Approval All procedures performed in studies involving human participants were in accordance with the ethical standards of the institutional and/or national research committee and with the 1964 Helsinki declaration and its later amendments or comparable ethical standards. This article does not contain any studies with animals performed by any of the authors.

Informed Consent This study is a retrospective analysis using a deidentified data set and does not meet the criteria for human subjects research. The UMass Donahue Institute received de-identified, individual level data from Guardian Ad Litem Services (GAL). All participants in this study are clients of GAL whose mental illness has reached a level of severity that a guardian/conservator has been assigned. Upon enrollment in the GAL program, each individual's conservator meets face to face with GAL staff and is presented with release forms from each hospital that the individual has been a patient in, as well as from the Department of Corrections. GAL staff verbally explain that these release forms allow GAL to obtain medical and legal data about its participants, which is used both to aid in case management of the individual and in analyses of program effectiveness. Data are only collected from institutions for which appropriate release forms have been signed.

Open Access This article is licensed under a Creative Commons Attribution 4.0 International License, which permits use, sharing, adaptation, distribution and reproduction in any medium or format, as long as you give appropriate credit to the original author(s) and the source, provide a link to the Creative Commons licence, and indicate if changes were made. The images or other third party material in this article are included in the article's Creative Commons licence, unless indicated otherwise in a credit line to the material. If material is not included in the article's Creative Commons licence and your intended use is not permitted by statutory regulation or exceeds the permitted use, you will need to obtain permission directly from the copyright holder. To view a copy of this licence, visit http://creativecommons.org/licenses/by/4.0/.

\section{References}

American Psychiatric Association. (2013). Diagnostic and statistical manual of mental disorders (5th ed.). Arlington, VA: American Psychiatric Publishing.

Bureau of Labor Statistics. (2018). CPI inflation calculator. Retrieved June 1, 2018, from https://www.bls.gov/data/inflation_calculator .htm.

Burley, M. (2011). Public guardianship in Washington state: Costs and benefits (Document No. 11-12-3902). Retrieved June 1, 2018, from Washington State Institute for Public Policy website, https 
://www.wsipp.wa.gov/ReportFile/1097/Wsipp_Public-Guardiansh ip-in-Washington-State-Costs-and-Benefits_Full-Report.pdf.

Cochrane Effective Practice and Organisation of Care. (2017). Interrupted time series (ITS) analyses. Ottawa: Cochrane EPOC Resources for Review Authors.

Connecticut Department of Mental Health. (2015). Mental disorders by age group and payer, FY2011-15. Retrieved June 1, 2018, from Office of Health Care Access website, https://portal.ct.gov/DPH/ Office-of-Health-Care-Access/CT-MONAHRQ/Inpatient-Disch arges-and-Emergency-Room-Visits.

Cook, T., \& Campbell, D. (1979). Quasi-experimentation: Design and analysis issues for field settings. Chicago, IL: Rand McNally.

Mackniak, M. (2016). Saving Melissa: 7 Cs to cure the mental health system. Middlebury, CT: Conservative Care Inc.

McDonald, K., Sundaram, V., Bravata, D., Lewis, R., Lin, N., Kraft, S.,..., Owens, D. (2004). Closing the quality gap: A critical analysis of quality improvement strategies (Volume 7: Care coordination). Technical Reviews, 9(7). Retrieved June 1, 2018, from Agency for Healthcare Research and Quality website, https:// www.ncbi.nlm.nih.gov/books/NBK44019.

Moye, J., Wood, E., Teaster, P., Catlin, C., \& Kwak, J. (2016). Examining the need for a public guardian in Massachusetts: Phase I. Retrieved June 1, 2018, from the Massachusetts Guardianship
Policy Institute website, https://massguardinstitute.org/pdf/resea rch/Mass.\%20Gdn.\%20Policy\%20Institute\%20--\%20Needs $\% 20$ Assessment $\% 20$ Phase $\% 201 \% 20$ Report.pdf.

Nicks, B., \& Manthey, D. (2012). The impact of psychiatric patient boarding in emergency departments. Emergency Medicine International, 360308, 5. https://doi.org/10.1155/2012/360308.

Snijders, T., \& Bosker, R. (2012). Multilevel analysis: An introduction to basic and advanced multilevel modeling (2nd ed.). Thousand Oaks, CA: Sage.

Teaster, P. B., Mendiondo, M. S., Schmidt, W. C., Marcum, J., \& Wangmo, T. (2009). The Florida public guardian programs: An evaluation of program status and outcomes. Lexington, KY: University of Kentucky Graduate Center for Gerontology.

Vera Institute of Justice. (2015). The price of prisons: Examining state spending trends, 2010-2015. Retrieved June 1, 2018, from https ://www.vera.org/publications/price-of-prisons-2015-state-spend ing-trends.

Publisher's Note Springer Nature remains neutral with regard to jurisdictional claims in published maps and institutional affiliations. 